\title{
Leading the Charge for SoTL - Embracing Collaboration
}

\author{
Anita Cassard, PhD \\ Dissertation Chair and Mentor, School of Advanced Studies \\ University of Phoenix \\ Brian Sloboda, PhD \\ Economist \\ US Department of Labor, Assistant Secretary for Policy
}

The scholarship of teaching and learning (SOTL) enables colleges and universities to assess student learning and measure the outcomes by engaging in meaningful research, and to disseminate this research. The objective of this paper is to give a snapshot of and assess the current thinking behind this scholarship by presenting examples of SoTL, and to provide insights into the measurement of SoTL research by faculty members. By presenting a carefully crafted research agenda in SoTL, colleges and universities can disseminate this research as a means of providing useful assessments of student learning and measurements of relevant outcomes.

"Education is the most powerful weapon which you can use to change the world." Nelson Mandela

Any educational operation can be deemed inefficient whenever faculty capacity goes unused, when policies dictate more restrictions than necessary to accomplish the work at hand, and when drivers at the decision-making wheel emphasize outdated and inefficient methods or models instead of serving faculty and student needs. Knowing what to look for is important, since there is usually warning signs of inefficiency that can also point to opportunities for cost savings and productivity increase.

The objective of this paper is to describe how a cross-disciplinary program promoting the scholarship of teaching and learning at colleges can provide value and richness. The division of this paper is as follows: Section 1 provides an overview of past and present practices; Section 2 provides a review of the literature addressing the promotion of cross-disciplinary research and its benefits; Section 3 provides examples of cross-disciplinary discourse in scholarly of teaching and learning activities; Section 4 provides measurement issues in SoTL research; and Section 5 concludes the paper with questions about the future of SoTL.

At many college campuses, students often express dismay about how academic-specific research impacts their learning. Boyer (1990), as well as Glassick, Huber, and Maeroff (1997) started promoting a shift from the traditional theme of a university to a new paradigm for recognizing the full range of scholarly activity by university faculty. As a consequence, many universities have created an environment that promotes the values of scholarship of teaching and learning. SoTL provides value-added, discipline-specific research, which most academicians pursue. Throughout many academic departments, it is now common to take an active role in the scholarship of teaching; the emergence of campus conversations among faculty members is leading to a promulgation of interests regarding teaching and learning practices that enhance learning based on the evidence of novel teaching practices.

\section{Section 1: Overview}

The Boyer Model, implemented as a major form of promoting faculty scholarship and used as a method of evaluation of faculty at many universities since its inception in the early 1990s (O'Meara, 2005), is being challenged by new ideas. The model was not welcomed by all academicians and created controversy by promoting faculty scholarship. Richlin (2001) alleged that SoTL is not clearly 
defined, and many members of academia view SoTL as an illegitimate form of research, claiming it ought not to be pursued as a serious form of research (Cunsolo, Elrick, Middleton \& Roy, 1996; Kreber \& Cranton, 2000; Ziolkowski, 1996). McKinney (2006) concluded that the SoTL is not linked to improved teaching practices at universities as originally proclaimed and intended. Despite diverse perspectives by academicians about SoTL, it has blossomed extensively in recent years, and still serves as a forum for faculty scholarship in congruence with the traditional research discipline.

In this paper, the term cross-disciplinary refers to faculty from different subject areas investigating and promoting more effective ways of teaching and learning. Cross-disciplinary efforts in promoting the scholarship of teaching and learning are crucial since they enhance the teaching and learning process, thereby creating avenues for faculty to understand how learning across the curriculum is possible. We need to ask ourselves, What are the structural variables in today's education, and how can we achieve educational sustainability? We can apply crossdisciplinary research in SoTL to: a) minimize toxic situations, b) enhance a prosocial environment, and c) create meaningful steps for

\section{Shifting power from the instructor to the student will presumably generate positive consequences such as increasing students' skills, instead of the sole focus being on grades.}

faculty and students alike. The face of higher education is changing and attracts more students from diverse backgrounds with different individualized cognitive needs. Because of these changes in higher education, educators must carefully assess their students in order to align the appropriate educational content and meet learning outcomes (Cantor, 1997). Caffarella and Barnett (1994) state the need to clearly identify the course objectives to the students early on, while emphasizing the content of the course. In addition, highlighting the contributions of student's work ought to be emphasized in the course design. That is, how can students contribute to the course by incorporating their perspectives? The goal in course development is to have students depend less on the guidance of the instructors but instead refine their comprehension of the course material via engaging in discussions with other students while the instructor serves as facilitator in the classroom (Benander, 2009). Shifting power from the instructor to the student will presumably generate positive consequences such as increasing students' skills, instead of the sole focus being on grades. Additionally, this shift will create an inclusive classroom that respects all backgrounds and prior knowledge. A good way to evaluate the accuracy of such actions and to uncover problem areas is to track planned versus actual deliverables.

We need more engagement of a broader type versus engagement as usual. Why do we produce content? Because we act as curators of that particular content, we can disperse this content to others. Educational ways change; we have to measure to learn in that environment, and we need to focus on what we understand and maximize that understanding. We need to create unique content and focus on the best distribution channels while simultaneously recognizing that these channels and tools (applications) come and go. For example, a recent study by Oxford predicts that almost 50 percent of US jobs will be replaced by robots and $\mathrm{Al}$ (Artificial Intelligence) over the next 20 years. For people involved in scholarly teaching and learning activities to understand these future trends is important, and represents an opportunity to reinvent and overhaul the past and present systems. It is the tsunami of education; stay on top of it, or be washed away.

\section{Section 2: Examples of SoTL Literature Review}

One of the main characteristics of the SoTL domain is that SoTL steers faculty toward discussion, peer review, and research to improve teaching strategies. That is, the SoTL movement tends to focus more heavily on the faculty. One of the main deliverables of scholarly research from SoTL is a comprehensive literature 
review. One of the far-reaching developments in SoTL is the institutional culture supporting SoTL by the faculty actually producing it (Cox, 2003; Kreber, 2001; Theall \& Centra, 2001). This section presents more examples of SoTL that do not only focus on discussions, peer review, and research, resulting in a review of the literature (Albers, 2008; Waterman et al., 2010).

Tenenberg and Wang (2005) present an example about a concern among faculty in computer science at both two-year and four-year institutions to ensure a smooth transition for students between institutions. They describe a collaborative effort in bridging these institutional divides by opening classrooms to other faculty members as a means to critically examine the pedagogical methods and assess student outcomes from this learning. They examine the student work submitted, looking for student learning, and this critical examination of student learning is achieved through the development of course portfolios for each course that is taught. The portfolios are used to examine different courses within a discipline and curricula across the institutions. From this introspection, they can obtain lessons about the assessment of their teaching in their courses and the use of course portfolios as a means for disseminating knowledge and developing new practices to promote learning.

Tenenberg and Wang's (2005) approach holds uniform in the classroom the variances in educational backgrounds, learning styles, aptitudes, and time/energy constraints. As a consequence, many educators design classroom activities by "aiming down the middle," which is not necessarily the best strategy to encourage strong pedagogy. In fact, League (2008) states many academicians would simply disregard the lower half of a class rather than risk extinguishing the enthusiasm of the best and brightest by moving too slowly in the presentation of the course material. To improve pedagogy resulting in improved student outcomes that League (2008) developed in an undergraduate course in artificial intelligence, a workbook-style of lab assignments was developed in accordance with Bloom's taxonomy to cover all aptitudes and learning styles. The development of the workbook style lab assignments would create a disciplinary commons that includes a repository of source code, lecture notes, homework exercises, and additional learning activities. Course portfolios as espoused by Tenenberg and Wang (2005) provide an important model for meeting the criteria for SoTL work to promote interdisciplinary teaching, and are able to document the complex processes by which faculty and students engage in interdisciplinary problem-solving (Bernstein, Burnett, Goodburn, \& Savory, 2006).

Wilner (2009) describes an ongoing faculty development project called BRIDGE (Bridging Research, Instruction, and Discipline-Grounded Epistemologies) that draws upon the insights of Angelo and Cross (1993), who stated that effective classroom techniques also include effective teaching strategies, and that these strategies differ from institutional program assessment because of their focus on specific teaching environments. The success of BRIDGE focuses on the simultaneity of the discipline-based classroom research and multi-disciplinary workshops. This two-pronged approach allows faculty to connect pedagogy with the epistemologies that underlie their own training (the former) while the latter approach confers a number of advantages that enhance both faculty satisfaction and leading to successful classroom research. The main thrust of BRIDGE is the "going public" approach at the end of the academic year, in which faculty share their methods and find and solicit peer review. The solicitation of peer review confirms the scholarly nature of their work and provides motivation for other educators to build upon these approaches.

Jaafar and Baishanski (2012) developed an integrative approach to learning in introductory STEM (Science, Technology, Engineering, and Mathematics) courses and related courses. More specifically, they applied their case study 
approach in a college algebra course by incorporating cross-curricular skills, and this approach measures the effectiveness of course outcomes by analyzing student work on the project and responses to surveys throughout the course. The results find the assignment affects students' mastery of specific quantitative skills positively, their perceptions of learning are improved, and they develop a stronger appreciation for the relevance of studying mathematics, especially at the introductory level. Because of the uniqueness of introductory courses, Jaafar and Baishanski carefully crafted suggested guidelines for designing course activities with the objective to teach the whole student in these courses.

Waterman et al. (2010) provided a collaborative example of the Scholarship of Teaching and Learning Fellows Program at Southeast Missouri State University. This program enrolls an annual cohort of 10 faculty fellows to evaluate, through individual research projects, the effectiveness of their teaching on student learning of at least two of the university's general education courses. This program is meant to be an interactive collaborative peer consultation. The colleagues meet monthly to address the research questions and consult with their peers as they progress through their research as applied to their specific research projects. At the conclusion of the academic year, these Fellows present their research to the university community. An analysis of three cohorts from the program showed that $66 \%$ of the projects had coherent outcomes that showed measurable impacts on student learning. More specifically, these surveyed Fellows impacted over 4,500 students in 100 courses. Most of the projects emphasized a new teaching approach, new curriculum materials, integrated applications, and active learning. Some of the Fellows presented their research at professional conferences and seven of them published their research results in scientifically reviewed journals. The feedback by the Fellows revealed this program as a positive influence on their teaching and research.

\section{Section 3: Examples of cross-disciplinary discourse of the SoTL}

Because of some of the difficulties involved in communicating among crossdisciplinary programs, it may be beneficial to look at tools such as information mapping. Information mapping is based on how the mind processes and retrieves memorized and read information. It is an alternative to conventional reading and provides an integrated set of easy-to-learn-and-understand guidelines and techniques for analyzing user needs. Information mapping organizes the information into manageable blocks or pods that can be maintained and reused, and presents the information in a format that is easy to find and understand.

In addition, do we as faculty and educators need training on root cause analysis? Valuable SoTL knowledge resides with faculty and is contained at a specific point. However, from a cross-disciplinary standpoint, a sense of meaning and shared communication is absent. Critical data and information is not shared, and we have developed a culture of passivity. In most cases, education-specific knowledge is deeply engrained and becomes part of the way things are done, thus becoming an unconscious competence.

Kuh and I kenberry (2009) created a survey with responses from provosts for the National Institute for Learning Outcomes Assessment aiming to understand student learning assessment. The report stated "Gaining faculty involvement and support remains a major challenge..." Sixty-six percent of provosts at all institutions said more faculty engagement would be helpful, and "about four-fifths of provosts at doctoral research universities reported greater faculty engagement as their number one challenge" (p. 24).

Milton Cox, director of the Center for the Enhancement of Learning and Teaching at Miami, describes Miami University of Ohio as "multi-disciplinary groups of 6 to 15 members...they work collaboratively on nine-month, scholarly programs to enhance teaching and learning" (p. 92). He reports that 
the learning communities built high levels of trust through participative decision-making. The ensuing sense of community and the scholarship of teaching and learning provided the social dynamics and the intellectual linkage between theory and practice for successful change management. The capacity building inherent in learning communities fed off itself because successful graduates of the program are now facilitators of subsequent learning communities. (2006, p. 97)

In spite of the changes in universities to encourage more scholarly activities across the curriculum, each discipline has its own unique history and debates in the discipline and the methodological approaches that influence how it is taught, the content of what is taught, to whom, and why it is taught. More specifically, each discipline has its own style of pedagogical approaches, e.g., data analysis, computer programming, and problem sets in the business disciplines. In fact, each discipline's participants can actively engage in discussions related to research and pedagogy via peer-reviewed journals, its various associations, and conference venues that often promote scholarly exchange. However, researchers in SoTL must address discipline-specific issues if they wish to

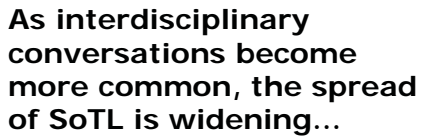

As interdisciplinary conversations become more common, the spread of SoTL is widening...

be heard in their discipline and interact with their colleagues in a language they understand. That is, not all disciplines speak in the same language, and Joseph Schwab (1964) describes it elegantly as "substantive and syntactic structures," the "conceptions that guide inquiry" and the "pathways of enquiry [scholars] use, what they mean by verified knowledge and how they go about this verification" ( $p .25$ ).

Those engaged in SoTL acknowledge these differences across disciplines and do not view them as a barrier to promoting crossdisciplinary discussions, because each discipline has its own unique identity and style that can be woven across disciplines. Members of each discipline have the goal to expand the borders of the discipline by examining new issues that can be researched, and SoTL as its own unique discipline can also examine new issues and further expand the discipline. One of the drawbacks of working across disciplines is that the literature is often obscured because of language, methods, and other specific concerns. However, there has been a growth of forums for crossdisciplinary conversations, and these forums have served as a bridge for the literature across disciplines and greater access to outside members of a discipline. As interdisciplinary conversations become more common, the spread of SoTL is widening into what historian of science Peter Gallison (1997) calls a "trading zone" (781-884). In reference to Gallison, scholars across disciplines could come together and share their ideas, insights, and findings despite the differences in language, methodological approaches, and contemporary discussions.

It can be inferred that scholars in their respective disciplines work with the traditional approaches of teaching and learning and are often not fully aware of those in their disciplines that are actively engaged in SoTL. There is a wave of change occurring in academia today that is attributed to technological changes, greater emphasis on accountability, and other factors that bring teaching and learning into focus. Given the latter, what happens when academicians become more interested in examining more closely their own teaching, assessing student learning, and sharing their findings with their colleagues?

\section{Section 4: Measurement of SoTL Scholarship Activities}

One of the major, persistent difficulties in the measurement of SoTL activities is the lack of coherence in the definition of SoTL, and this lack of coherence makes it difficult for the colleges and universities to use this academic discourse towards academic promotion of faculty members (Andresen, 2000; Smith, 2001). The latter poses a challenge for academicians as a legitimate form of academic discourse (Boshier, 2009). Over the years, much effort has been 
expended to craft together various interpretations of SoTL through the development of models, e.g., Trigwell, Martin, Benjamin, and Prosser (2000) and Weston and McAlpine (2001). Despite this development, these models have difficulties in institutionalizing the concept of academic discourse of SoTL (Boshier, 2009), and these difficulties have persisted, resulting in a poor understanding of what it means in practice and how to measure the value and impact of SoTL research (Nicholls, 2004).

For scholarship to be valuable to a discipline, there is generally a process to evaluate its quality. Diamond (1993) summarized the criteria that are used to carefully examine scholarly contributions versus other types of academic work. These scholarly contributions require a solid understanding of the literature of the discipline, the scholarship contribution breaks new ground in the discipline, this scholarship can be replicated, the scholarly contribution can be documented, it can be peer-reviewed, and it contributes value-added to the literature of the discipline. The Carnegie Foundation for the Advancement of Teaching proposes a new set of standards for evaluating faculty scholarship contributions (Glassick et al., 1997). In fact, Glassick et al. (1997) posited that the traditional assessment of scholarship contributions that adhered to the Mertonian criteria are no longer applicable because these criteria were developed during a time when faculty members were evaluated exclusively on the advancement of knowledge, not scholarship activities in general. The advent of the Boyer's model in 1990 expanded the role of scholarship, because many faculty members also engage in scholarship activities other than the advancement of knowledge of the discipline. To complement Boyer, Glassick et al. (1997) proposed that all faculty members at a university "must be held to the same standards of scholarly performance" (p. 22). In fact, Glassick et al. (1997) proposed that the following six standards be applied when evaluating faculty scholarly contributions: the scholarship activity should have clear goals, require adequate preparation, make use of the appropriate methods, produce significant results, demonstrate effective presentation, and involve reflective critique (p. 25). However, these standards are not meant to decipher between competent and scholarly teaching. One of the difficulties in measuring SoTL contributions effectively is that SoTL is dominated by the orthodox principles of higher education. Consequently, the approach of these orthodox principles has led to the marginalization of SoTL as a field of study. In fact, the Carnegie Foundation states that SoTL "builds on many past traditions in higher education." These traditions include classroom management, the assessment of student learning, reflective practice, faculty development, peer review of the teaching faculty, and traditional educational research (Hutchings, 2007).

Peer review and the politics of publishing in SoTL seem to dominate. Some academicians have argued that much of the work in SoTL flows from top-down, teacher-centered and, in some cases, discredited approaches to teaching and learning. Because of these preoccupations, those in academic administration and tenure committees would have difficulties carefully assessing the contributions from SoTL. Some academicians are perplexed by this preoccupation because most teaching and most of the students' learning may not occur in formal classrooms. That is, knowledge may not always be acquired in a formal classroom setting. As a result, SoTL may need to expand the concept of learning to include both formal and informal learning settings. Perhaps the most marked notion of SoTL is that there is a general reluctance to define SoTL, and there is no agreement as to what constitutes SoTL. Consequently, leaders like Boyer and others merely turned this task over to market forces or even peer review. That is, if the SoTL scholarship activity passes peer review, then it is considered to be scholarship, and if the work is rejected, then it is not considered to be scholarship (Boshier, 2009).

Many academicians are engaged in scholarly work such as conference presentations, peer review of journal articles, publishing papers, and other scholarly activities. It becomes crucial to examine the institutional impact of the research in SoTL and document what students are learning and how; what they learn from these courses is migrating from student to student and even educational setting to 
another educational setting (Huber, 2009). As pointed out by Hutchings (2011), academicians who become engaged in SoTL may also be likely to be engaged in other scholarship activities as related to their respective disciplines. Consequently, this mix of SoTL and discipline-oriented scholarship can be complementary in some ways that are likely to become cumulatively even more significant over time. In fact, the integration of SoTL practice and its findings into pedagogical and curriculum initiatives like introductory courses, learning communities, service learning, undergraduate research, and other programs, could result in widespread improvements in learnings and outcomes that can be substantiated in SoTL. How does one make the latter a more recognizable and viable part of scholarship at a college or university? Some academicians may allude to the fact that research in SoTL is purely qualitative and not substantiated with empirical data to evaluate the effectiveness of the teaching methods and outcomes. That is, in many disciplines, SoTL tends to focus on teachers, teaching strategies, teaching situations, and teaching assignments. In fact, Badley (2003) suggests there is the challenge of increasing the emphasis of this work on learning. To substantiate further, according to McKinney (2006), teachers and teaching strategies, situations, and assignments are all worthy topics to examine in detail, but the research in these latter topics needs to focus more on student outcomes and affective and cognitive processes.

\section{Section 5: What is the Future of SoTL?}

It is quite possible that colleges and universities may need to provide evidence of learning outcomes from their academic programs. Because of the requirements of these outcomes, strong research design from SoTL could serve as a prerequisite of providing the effectiveness of this learning. Accountability is not a new concept in higher education, and there is a greater push for showing accountability from colleges and universities. Secretary of Education Margaret Spellings convened the Commission on the Future of Higher Education, and the primordial conclusion from this report (the Spellings Report) revealed the importance of assessment and accountability. In fact, this report did not recommend holding universities directly accountable, but rather supported the ideal of improved quality and accountability in higher education.

We believe that improved accountability is vital to ensuring the success of all the other reforms we propose..Student achievement, which is inextricably connected to institutional success, must be measured by institutions on a "value-added" basis that takes into account students' academic baseline when assessing their results. This information should be made available to students, and reported publicly in aggregate form to provide consumers and policymakers an accessible, understandable way to measure the relative effectiveness of different colleges and universities. (Spellings report, p. 4)

Hutchings, Huber, and Ciccone (2011) argued in favor of reconsidering the scope of SoTL, believing it to be a critical set of principles and practices in achieving institutional goals for the betterment of students' achievements. In response to calls for enhanced quality in higher education and greater accountability, some states may legislate broad testing requirements for graduating college seniors. If colleges and universities are mandated to carry out such assessments, they will likely turn to the departments within their colleges to provide them. Consequently, there will be a greater need for published literature on student learning in various academic disciplines that will provide the necessary means to be more proactive in meeting these legislative mandates (Charlevoix, 2008). In the face of the evidence of this important understanding, what is the true north of academia? What is the vision? Higher education may need to extend its reach and inspire to convey clear 
intentions while at the same time transform internal rigid cultures, and engage and inspire faculty to accelerate innovation. Who will lead the charge?

\section{References}

Albers, C. (2008). Improving pedagogy through action learning and scholarship of teaching and learning. Teaching Sociology, 36(1), 79-86.

Andresen, L. W. (2000). A useable, trans-disciplinary conception of scholarship. Higher Education Research \& Development, 19(2), 137-153.

Angelo, T. A., \& Cross, K. (1993). Classroom assessment techniques: $A$ handbook for college teachers $\left(2^{\text {nd }}\right.$ ed.). San Francisco, CA: Jossey-Bass.

Badley, G. (2003). I mproving the scholarship of teaching and learning. Innovations in Education and Teaching International, 40, 303-309.

Benander, R. (2009). Experiential learning in the scholarship of teaching and learning. Journal of Scholarship of Teaching and Learning, 9, 36-41.

Bernstein, D. A., Burnett, N., Goodburn, A., \& Savory, P. (2006). Making teaching and learning visible: Course portfolios and the peer review of teaching. Bolton, MA: Anker Publishing.

Boshier, R. (2009). Why is the scholarship of teaching and learning such a hard sell? Higher Education Research \& Development, 28(1), 115.

Boyer, E. L. (1990). Scholarship reconsidered: Priorities of the professoriate. San Francisco, CA: Jossey-Bass.

Cantor, J. A. (1997). Experiential learning in higher education: Linking classroom and community. Washington, D.C: The George Washington University Graduate School of Education and Human Development.
Caffarella, R. S., \& Barnett, B.G (1994). Experiential learning: A new approach. In L. Jackson and R. S. Caffarella (Eds.), Characteristics of adult learners and foundations of experiential learning (pp. 29-42). San Francisco, CA: Jossey-Bass.

Charlevoix, D. J. (2008). Improving teaching and learning through classroom research. American Meteorological Society, 89(11), 1659-1664.

Cox, M. D. (2003). Proven faculty development tools that foster the scholarship of teaching in faculty learning communities. To I mprove the Academy, 21, 109-142.

Cox, M. D., Hunt, L., Bromage, A., \& Tomkinson, B. (2006). Phases in the development of a change model. The realities of change in higher education, pp. 91-100. New York, NY: Routledge.

Cunsolo, J., Elrick, M., Middleton, A., \& Roy, D. (1996). The scholarship of teaching: A Canadian perspective with examples. The Canadian Journal of Higher Education, 26(1) 35-56.

Diamond, R. M. (1993), Changing priorities and the faculty reward system. New Directions for Higher Education, 1993(81), 5-12. doi: $10.1002 /$ he. 36919938103

Gallison, P. (1997). Image and logic: A material culture of microphysics. Chicago, IL: University of Chicago Press.

Glassick C., Huber, M., \& Maeroff, G. (1997). Scholarship assessed: Evaluation of the professoriate. San Francisco, CA: Jossey-Bass. 
Hutchings, P., Huber, M., \& Ciccone, A. (2011). Getting there: An integrative vision of the scholarship of teaching and learning. International J ournal for the Scholarship of Teaching and Learning, 5(1). Retrieved from http://digitalcommons.georgiasouthe rn.edu/ij-sotl/vol5/iss1/31

Hutchings, P., Huber, M., \& Ciccone, A. (2011). Why the scholarship of teaching and learning matters today. San Francisco, CA: Jossey-Bass.

Hutchings, P. (2007). Theory: The elephant in the scholarship of teaching and learning room. International Journal for the Scholarship of Teaching and Learning, 1(1), 1-4.

Jaafar, R., \& Baishanski, Y. (2012). Developing cross-disciplinary competencies through college algebra. Insight: A Journal of Scholarly Teaching, 7, 17-30.

Kreber, C. (2001), The Scholarship of Teaching and Its I mplementation in Faculty Development and Graduate Education. New Directions for Teaching and Learning, 2001(86), 79-88. doi: 10.1002/tl.18

Kreber, C., \& Cranton, P. A. (2000). Exploring the scholarship of teaching source. The Journal of Higher Education, 71(4), 476-495.

Kuh, G., \& Ikenberry, S. (2009). More than you think, less than we need: Learning outcomes assessment in American higher education. National Institute for Learning Outcomes Assessment. Retrieved from http://learningoutcomesassessment. org/ NI LOAsurveyresults09. htm

League, C. (2008). Something for everyone: Al lab assignments that span learning styles and aptitudes. Journal of Computing Sciences in Colleges, 23(5), 142-149.
McKinney, K. (2006). Attitudinal and structural factors contributing to challenges in the work of the scholarship of teaching and learning. New Directions for Institutional Research, 129, 37-50.

Nicholls, G. (2004). Scholarship in teaching as a core professional value: What does this mean to the academic? Teaching in Higher Education, 9(1), 29-42.

O'Meara, K. A. (2005). Encouraging multiple forms of scholarship in faculty reward systems: Does it make a difference? Research in Higher Education, 46(5), 479-510.

Richlin, L. (2001). Scholarly teaching and the scholarship of teaching. New Directions in Teaching and Learning, 86, 57-68.

Schwab, J. (1964). Structure of the disciplines. In G. W. Ford \& L. Pugno (Eds.), The Structure of Knowledge and the Curriculum. Chicago, IL: Rand McNally.

Smith, R. (2001). Expertise and the scholarship of teaching. New Directions for Teaching and Learning, 86, 69-78.

Spellings, M., (2006). A Test of Leadership: Charting the Future of U.S. Higher Education. Final report of the Secretary of Education's Commission on the Future of Higher Education. Retrieved from https://www2.ed.gov/about/bdscom $\mathrm{m} /$ list/hiedfuture/reports/finalreport. pdf/about/bdscomm/list/hiedfu ture/reports/ final-report.pdf

Tenenberg, J., \& Wang, Q. (2005). Using course portfolios to create a disciplinary commons across institutions. Journal of Computing Sciences in Colleges. 21(1), 142-149.

Theall, M. and Centra, J. A. (2001), Assessing the Scholarship of Teaching: Valid Decisions from Valid Evidence. New Directions for Teaching and Learning, 2001(86), 31-43. doi: 10.1002/tl.14 
Trigwell, K., Martin, E., Benjamin, J., \& Prosser, M. (2000). Scholarship of Teaching: A model. Higher Education Research \& Development, 19(2), 155168.

Waterman, M., Weber, J., Pracht, C., Conway, K., Kunz, D., \& Evans, B. (2010). Preparing scholars of teaching and learning using a model of collaborative peer consulting and action research. International J ournal of Teaching and Learning in Higher Education, 22(2), 140-151.
Weston, C. B., \& McAlpine, L. (2001). Making explicit the development toward the scholarship of teaching. New Directions for Teaching and Learning, 86, 89-97. Wilner, A. (2009). Engaging faculty in scholarship of teaching and learning: A view from BRIDGE. Unpublished manuscript, Rider University, Lawrenceville, NJ .

Ziolkowski, E. J. (1996). Slouching toward scholardom: The endangered American college. College English, 58(5), 568-588.

Anita Cassard completed her undergraduate coursework at the Economic Research Institute and Institute of Advanced Studies in Vienna/Austria. She received her MPS from The New School University (Milano-The New School for Management and Urban Policy) NYC in Hospital and Health Care Administration and her doctoral degree from Walden University in Minneapolis (Applied Management and Decision Sciences) specializing in Leadership and Organizational Change. She collaboratively wrote papers published in peer reviewed, scientific journals such as JSBHS- Journal of Social, Behavioral, and Health Sciences. Her book The Sherpa Leadership Model: A Model of Disempowerment; was published in Europe and the United States by VDM-Publishing in Germany.

Brian W. Sloboda is currently an economist at the U.S. Department of Labor, Assistant Secretary for Policy. He also teaches courses in economics and statistics at the University of Phoenix and Park University. Brian has published articles in the Journal of Economics, Current Politics and Economics in Africa, Advances in Econometrics, Annals of Regional Science, Advances and Applications in Statistics, Tourism Economics, Journal of Transportation and Statistics, Pennsylvania Economic Review, International Journal of Transport Economics, Journal of Business and Economic Perspectives, and the Virginia Economic Journal. He also edited, Transportation Statistics (2009) by J Ross and also co-edited Econometric and Forecasting Models (2013) with Chandrasekhar Putcha and Kalamogo Coulibaly by Mellen Press. 